more strongly modified. Films on zinc oxide were always blue, with almost infinite resistance. Films $70 \mathrm{~A}$. in thickness (on a weight-bulk density basis) on bismuth oxide were, however, of a pale-straw colour, and had a resistance of about $15 \mathrm{ohms}$ between opposite edges of a square sample. The transmission factor for white light was about 70 per cent. On heating such a sample to $200^{\circ} \mathrm{C}$. for a few minutes the colour became paler still, the transmission factor rose to about 73 per cent, and the resistance dropped to about $10 \mathrm{ohms}$. Moreover, these results were very closely reproducible from sample to sample. For comparison, it is to be noted that a similar film on glass cleaned by ordinary methods would be bluegreen in colour, and have a transmission of about 65 per cent and resistance of unpredictable value in a range of roughly $80-200 \mathrm{ohms}$.

It is further of interest to note that, with these films of gold on a substrate of oxide, the transmission can be further enhanced by using various methods analogous to 'blooming'.

For the moment, the structure of the highly conducting films is a matter of speculation but is being immediately investigated. It is, however, remarkable that the resistance value obtained is very close to the theoretical value for a plane-parallel lamina having the same weight of gold per unit area as the actual film. It seems also that the low optical absorption may be consistent with the optical constants for gold in bulk, with some form of 'thinness' correction, though this has not yet been fully investigated.

Whatever film-structure may be revealed by further examination, this work appears to offer an interesting new field for the study of surface forces and states, as well as providing for practical applications a transparent film of a novel type and exceptionally low resistance. It is understood that the Ministry of Supply, for which the research is being undertaken by the .National Physical Laboratory, is actively engaged in studying the problems of producing and using windows having a coating of this double-layer film.

${ }^{1}$ Nature, 169, 829 (1952).

\section{HOMING ABILITY IN BIRDS}

A RECENT issue of Ibis contains two important A articles on the direction-finding abilities of birds $(94$, No. 2$)$.

In the first article G. V. T. Matthews describes an extensive series of homing experiments carried out with 249 lesser black-backed gulls (migratory species) and 91 herring gulls (a restricted nomad), together with twenty other sea birds. On release the lesser black-backed gulls showed a significant homeward orientation which was absent when the sun was obscured by clouds; some direct evidence and an analysis of the homing success indicated that a large proportion of the gulls were homing by an inefficient method, probably random exploration for known visual landmarks. A minority, however, were homing by a method not dependent on the distance or area of release, the orientation behaviour suggesting some form of sun navigation. The herring gulls showed a much lesser ability to 'home', and this could be explained by there being a much smaller proportion of able navigators among them. Matthews also carried out experiments in which the earth's magnetic field was masked by airborne magnets; this in no way affected homing ability.
In the second article Gustav Kramer describes experiments carried out with starlings and homing pigeons. The starling's ability to reproduce constant compass directions was demonstrated in two ways : first, by using migratory activity as an indicator, the bird tending to take up a constant direction; second, by training the birds to choose one of several (up to twelve) feeders symmetrically distributed around the cage. If the incidence of light were changed by use of a mirror arrangement the direction chosen by the bird changed correspondingly. The sun was shown to be a governing factor, the orientation faculty (in experimental conditions) vanishing if the sun were hidden. The correct direction was reproduced regardless of the time of day.

Experiments with homing pigeons showed that these birds were able to home over an unknown stretch of two hundred miles. Some sort of astronomical navigation is suggested by the fact that the pigeons seemed to be orientated even before starting. Apart from this orientation method direction, learning could be produced by training the pigeons along one homing line; by displacing the bird sideways they are misled, this being taken as the test of direction learning.

Like starlings, pigeons were trained to choose food from a definite direction under experimental conditions, and here again the sun was the physical clue for orientation.

\section{BRITISH COAL UTILIZATION RESEARCH ASSOCIATION REPORT FOR 1951}

$\mathrm{W}$ ITH an annual fuel crisis tending to become an accepted feature of British life, means of increasing the output of coal from all indigenous sources have been widely publicized and implemented, so that coal production has been rising steadily during recent years. The nation's fuel problem remains, however, for coal consumption has also increased, so that now a gap exists between demand and supply which will doubtless widen unless and until coal is used more wisely and far more efficiently than at present. It is gratifying to note, therefore, that the resources of the British Coal Utilization Research Association are being devoted to bringing "in our time" a real improvement in the efficiency of using coal in all its conditions of availability.

Progress towards that aim is described in the annual report of the Association*, which was presented by the president, Sir Charles Ellis, to the annual general meeting on May 7. The many investigations being pursued include a new method of conditioning slurry, the automatic control of coalfired gas producers, the reduction of smoke from domestic open fires, and the use of coal for chemical purposes.

Several million tons of wet coal slurry are produced each year in colliery washeries. As produced, the slurry is a water-logged aggregate which, even after dewatering, is too finely divided to hurn satisfactorily. If it could be converted into a usable form, however, this material would make a substantial contribution to the nation's fuel supplies. A pelleting process has

* British Coal Utilization Research Association : Annual Report for 1951. Pp. 52. (Leatherhead : the Association, 1952.) 